\title{
Perceived physical activity during stay-at-home COVID-19 pandemic lockdown March - April 2020 in Polish adults
}

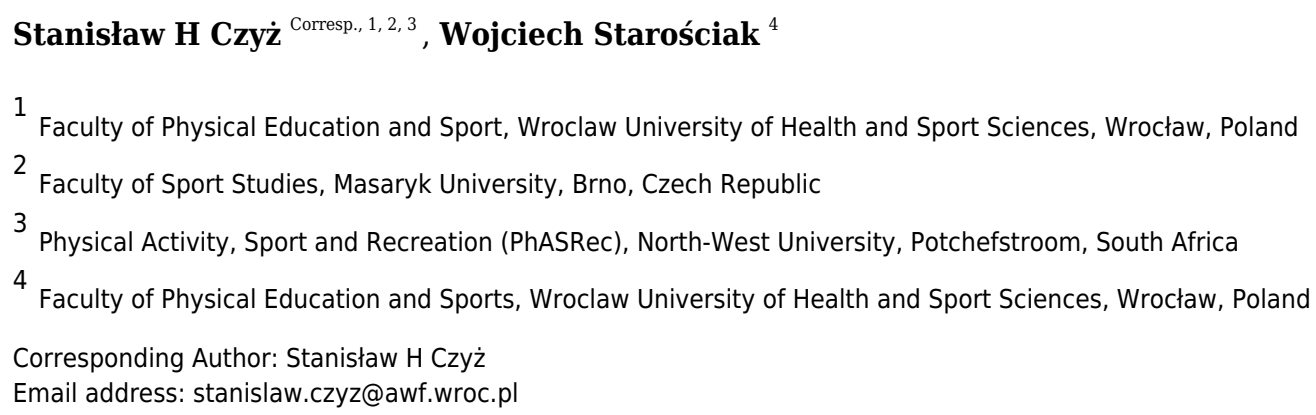

Background. Lockdowns amid the COVID-19 pandemic drastically reduced the possibility of undertaking physical activity (PA) in gyms, swimming pools, or work-related PA, e.g., active commuting. However, the stay-at-home order could have reduced PA the most, i.e., the ban of unnecessary outdoor activities. It affected free walking, running, skiing, active tourism, etc. It is, therefore, crucial to estimate how the stay-at-home order affected PA. We estimated how the stay-at-home order affected perceived PA and sedentary behavior compared to the pre-pandemic time in Poland. Methods. We used a self-reported International Physical Activity Questionnaire - Long Form (IPAQ-LF) to estimate the time (minutes per day) of vigorous and moderate PA and walking and sitting time. Results: We gathered data from 320 Polish participants. Bayesian approaches, including t-test and Bayesian correlations, were used to find differences and correlations between PA before and during the stay-at-home lockdown. Our data supported the hypotheses that vigorous PA, as well as walking, declined during the lockdown. Surprisingly, our data did not support the hypothesis that moderate physical activity was reduced. We found that moderate PA during lockdown increased compared to the pre-lockdown PA. As hypothesized, our data strongly evinced that sitting time inclined during the lockdown. PA decline was not correlated with the available living space. People who had access to gardens did not demonstrate a higher PA level than those without. Discussion: Walking and sitting time have drastically changed during the stay-at-home lockdown, decreasing and increasing, respectively. Given results from studies focusing on lockdowns without the stay-at-home restriction, it may be assumed that letting people go outside is crucial in keeping them more active and less sedentary. Authorities should take into account the effect the stay-athome order may have on PA and sedentary behavior and, as a result, on health. Stay-athome orders should be the last considered restriction, given its detrimental consequences. 


\section{Perceived physical activity during stay-at-home}

2 COVID-19 pandemic lockdown March - April 2020 in

3 Polish adults

Stanisław H. Czyż 1,2,3*, Wojciech Starościak ${ }^{1}$

${ }^{1}$ Faculty of Physical Education and Sports, Wroclaw University of Health and Sport Sciences, Wroclaw, Poland

${ }^{2}$ Faculty of Sport Studies, Masaryk University, Brno, Czech Republic

${ }^{3}$ Physical Activity, Sport and Recreation (PhASRec), Faculty of Health Sciences, North-West University, South Africa

* Corresponding Author: Stanisław H. Czyż, stachu.czyz@gmail.com;

\section{Abstract}

Background. Lockdowns amid the COVID-19 pandemic drastically reduced the possibility of undertaking physical activity (PA) in gyms, swimming pools, or work-related PA, e.g., active commuting. However, the stay-at-home order could have reduced PA the most, i.e., the ban of unnecessary outdoor activities. It affected free walking, running, skiing, active tourism, etc. It is, therefore, crucial to estimate how the stay-at-home order affected PA. We estimated how the stay-at-home order affected perceived PA and sedentary behavior compared to the pre-pandemic time in Poland.

Methods. We used a self-reported International Physical Activity Questionnaire - Long Form (IPAQ-LF) to estimate the time (minutes per day) of vigorous and moderate PA and walking and sitting time.

Results: We gathered data from 320 Polish participants. Bayesian approaches, including t-test and Bayesian correlations, were used to find differences and correlations between PA before and during the stay-at-home lockdown. Our data supported the hypotheses that vigorous PA, as well as walking, declined during the lockdown. Surprisingly, our data did not support the hypothesis that moderate physical activity was reduced. We found that moderate PA during lockdown increased compared to the pre-lockdown PA. As hypothesized, our data strongly evinced that sitting time inclined during the lockdown. PA decline was not correlated with the available living space. People who had access to gardens did not demonstrate a higher PA level than those without.

Discussion: Walking and sitting time have drastically changed during the stay-at-home lockdown, decreasing and increasing, respectively. Given results from studies focusing on 
lockdowns without the stay-at-home restriction, it may be assumed that letting people go outside is crucial in keeping them more active and less sedentary. Authorities should take into account the effect the stay-at-home order may have on PA and sedentary behavior and, as a result, on health. Stay-at-home orders should be the last considered restriction, given its detrimental consequences.

\section{Introduction}

COVID-19 pandemic lockdown policies have substantially reduced physical activity (PA) and increased sedentary behavior (Stockwell et al., 2021). International organizations and politicians argued that specific measures must be taken (United Nations Department of Economic and Social Affairs, 2020). As a result of these conjectures, PA recommendations during the COVID19 pandemic have been widely published (Hammami et al., 2020; Pinto et al., 2020; World Health Organization, 2020). There are already a few estimations of how lockdowns affected the level of PA and how the inactivity caused by pandemic lockdowns may affect health (King et al., 2020).

Given that PA has been generally and globally decreasing (Guthold et al., 2018) and its insufficiency affects health in many dimensions (Lee et al., 2012; Ekelund et al., 2016), the question of whether lockdowns further reduced it is vital. A review by Caputo and Reichert (Caputo and Reichert, 2020) included 41 studies related to PA and Covid-19 pandemic. They evinced that pandemic restrictions decreased PA. In another review, Stockwell and colleagues (Stockwell et al., 2021) emphasized that most of the 66 reviewed studies demonstrated a decline in PA and an incline in sedentary behavior. These trends were observed regardless of the subpopulation studied or the methodology used (Stockwell et al., 2021). A survey on PA amid pandemic in Canada (Rhodes et al., 2020) showed that perceived moderate (MPA) to vigorous physical activity (VPA) decreased. Meyer and colleagues (Meyer et al., 2020) reported a significant decrease in PA in socially isolated participants (staying at home) in the USA. A crosssectional study by Qin and colleagues(Qin et al., 2020) showed that the number of Chinese with inadequate PA was doubled during the pandemic compared to the world prevalence before the pandemic.

Nevertheless, a few studies were showing the opposite, e.g., participants who were able to go outside did not reduce their PA compared to the pre-pandemic activity (Meyer et al., 2020). Walking time (Walking) and MPA during the pandemic increased in Switzerland and France (Cheval et al., 2020). In Germany, sports-related activities declined while recreational increased (Schmidt et al., 2020).

Different approaches can partially explain these contradictory findings. Some studies were done with staying-at-home participants (stay-at-home order), some when outside activities, such as 
walking or running, were allowed. Moreover, some of the methods used to estimate PA during pandemic may be questioned. For instance, in a study using apps counting steps (Tison et al., 2020), PA was assessed based on smartphone applications. However, the probability of walking at home with a smartphone in hand seems rather dubious. Moreover, some people could have exercised at home without going out, e.g. they could engage in strength training, yoga, or other activities not requiring much locomotion. Home-based training may efficiently reduce the negative impact of decreased PA due to pandemic restrictions, e.g., a home-based resistance training proved to be a low-cost, efficient alternative to outdoor activities during the stay-athome lockdown in Italy (Vitale et al., 2020).

Therefore, it is crucial to estimate PA and sedentary behavior relating to the specific context because of restrictions in a studied country. We aimed to assess PA during the most restrictive lockdown in Poland. Given all restrictions and results from the previous studies, we advanced the hypotheses that $V P A, M P A$, and Walking will be much reduced during lockdown compared to the pre-lockdown period. However, the magnitude of that difference was unclear. We also advanced a hypothesis that sitting time (Sitting) before lockdown will be shorter than during lockdown.

\section{Materials \& Methods}

\section{Study design}

The study was approved by the Ethics Committee of the University School of Physical Education in Wrocław, Poland (no. 10.2020). All procedures were performed in accordance with the Declaration of Helsinki (World Medical Association, 2013). All participants volunteered to participate in the study (by ticking the online box). Although the study was anonymous, i.e., we did not collect any personal data, we asked participants to consent by clicking an appropriate checkbox at the beginning of the online survey. Given the nature of the study, we did not predetermine the sample size, i.e., we tried to recruit as many participants as possible.

\section{Pandemic-related national health restrictions}

The data was collected during the epidemic state between $31^{\text {st }}$ March and $20^{\text {th }}$ April 2020. The following restrictions affecting PA during the lockdown were in place:

- Free movement of people was restricted;

- People were allowed to leave home in precisely specified cases, such as for a trip to one's work or business, for essential trips to family and relatives for care or caregiving, shopping trips to purchase food and essential supplies, medicines or pet supplies, visits to the doctor or to deal with urgent official matters, volunteering related to coronavirus help, dog walk (only one person at a time); 
119

120

121

122

123

124

125

126

127

128

129

130

131

132

133

134

135

136

137

138

139

140

141

142

143

144

145

146

147

148

149

150

151

152

153

154

155

156

157

158

159

- All public events were cancelled;

- All schools, universities, theaters, cinemas, cultural centers, restaurants, clubs, hairdressers, tattoo, beauty salons, gyms, sport clubs, libraries, zoo, public gardens, etc. were closed;

- Obligatory 14-day quarantine for all returning to the country;

- Foreigners were not allowed to enter the country;

- All flights from and to Poland, as well as other transport means (buses, trains, tourist border crossings), were canceled;

- Non-essential shopping centers and shops were closed;

- Children under 18 were not allowed to walk outside without a legal guide's assistance;

- Maximum 5 people during funerals and in churches were allowed;

- Access to parks, forests, boulevards, etc. was prohibited;

- Cars, bicycles, and other rent centers were closed;

- Limited personal contacts with the public or clients and between employees and reduction of employees in the workplace to the necessary minimum were allowed.

Penalties for not adhering to the restrictions policy were between 5 and 30 thousand PLN (about 1106 - 6640 EUR according to the National Polish Bank exchange course on $21^{\text {st }}$ April 2020). On $21^{\text {st }}$ April, the restrictions were loosened, including the permission to walk outside for other than listed purposes, e.g., for running, walking, cycling, etc. We decided to analyze the data gathered up to 21 st April since IPAQ-LF is a 7-day recall questionnaire, which means the questionnaire completed on the $21^{\text {st }}$ was referring to the lockdown period.

\section{Participants}

Due to the total lockdown, the ways we could recruit participants were quite limited. We decided to attract potential participants via social media, including Twitter, Facebook (personal, university alumni, physical activity societies, media, and other profiles), private emails, and via radio (interviews in Meloradio and Radio Wrocław) and TV (interview in a regional public TVP 3). Interviews and a short description, and an invitation to participate in the study, were published on the media web pages.

We included all adults who were not quarantined due to the Covid-19 during the surveyed period (the last seven days). Data of participants who did not tick the consent was not saved.

\section{Survey}

The survey was anonymous and was done using Google Forms. The link:

https://docs.google.com/forms/d/e/1FAIpQLSfeErFVyUGRav05JeG_iE7hJ5ITVfceyjfxuQ7F1OE3RBf1Q/viewform?vc $=0 \& \mathrm{c}=0 \& \mathrm{w}=1$ was used for further dissemination. For convenience, we also used shorter links: https://tiny.pl/7qd7j and https://bit.ly/aktywnoscpolakow.

The survey consisted of three parts. In the first part of the survey, we asked to thick the informed consent box and collected demographic data about sex, age (date of birth), height, body mass, living place size $\left(\mathrm{m}^{2}\right)$, a number of household inhabitants, accessibility to own garden, and social 
160

161

162

163

164

165

166

167

168

169

170

171

172

173

174

175

176

177

178

179

180

181

182

183

184

185

186

187

188

189

190

191

192

193

194

195

196

197

198

199

status (schoolchild, student, white-collar worker, worker, pensioner, unemployed). Participants were able to add their comments too (indicating, e.g., maternity leave).

In the second and third parts of the survey, we used IPAQ-LF. Since there is no more appropriate questionnaire than others (Terwee et al., 2010), we decided to apply IPAQ (Craig et al., 2003) as it is one of the most widely used questionnaires worldwide. It shows good reliability ( $\mathrm{r}=0.81$ ) and is the most reliable $(\mathrm{ICC}=0.97)$ physical activity questionnaire (Helmerhorst et al., 2012). We chose the long-form (Hagströmer et al., 2006) as it assesses the PA level related to four domains: (1) during self-powered transportation, (2) at work, (3) during household and gardening work, and (4) during leisure time, including exercise and sport participation. VPA refers to activities that take hard physical effort and make you breathe much harder than normal. MPA refers to activities that take moderate physical effort and make you breathe somewhat harder than normal. It also allows collecting detailed information about sedentary activity.

We used the reliable Polish version of the questionnaire (Biernat et al., 2007; Biernat, 2013). In the second part of the survey, we used IPAQ-LF to assess the PA level before the pandemic. We asked about seven typical days in January 2020. Although the IPAQ was not ensured to be so much retrospective and the reliability and validity of 3-4 months recall questionnaire could be doubted, we decided to collect the data nevertheless. The third part of the survey consisted of IPAQ-LF dedicated to assess PA level during lockdown (7 days recall).

\section{Data processing and truncation}

The time of PA was calculated according to the "Guidelines for data processing analysis of the International Physical Activity Questionnaire (IPAQ) - Short and long forms" (Sjöström et al., 2005). We processed the data following the rules of data cleaning, unreasonably data exclusion, minimum values inclusion, and truncation of data described by Sjöström and colleagues (Sjöström et al., 2005).

Based on the assumption that an average of eight hours per day is spent sleeping (Sjöström et al., 2005), five participants were excluded from further analysis. Their sums of all Walking, MPA, and $V P A$ time variables were greater than 960 minutes (16 hours) (Sjöström et al., 2005).

152 records of 111 participants were truncated, i.e., the variables total Walking, total MPA, and total $V P A$ were calculated, and then, if any of them exceeded 180 minutes ( 3 hours), they were truncated to 180 minutes.

Given the VPA, MPA, and Walking are multiplied by different coefficients in each PA domain, i.e., occupational, transport, household, and leisure-related PA, it was impossible to use the truncated time to calculate metabolic equivalents-minutes (MET). Instead of using METs as initially proposed by Sjöström and colleagues (Sjöström et al., 2005) we report the time (minutes per day) for each activity (VPA, MPA, and Walking). Time spent in VPA, MPA, and Walking are widely used measures of PA, e.g., they are used by World Health Organization (World Health Organization, 2010). 


\section{Data analysis}

201 We report descriptive statistics on VPA, MPA, Walking, and Sitting time (min/day).

202 Bayesian one-sided t-test was used to compare PA before and during the lockdown. We assumed 203 that VPA, MPA, Walking before lockdown > VPA, MPA, Walking during lockdown. The opposite 204 hypothesis was advanced concerning the sitting time, i.e., Sitting before lockdown $<$ Sitting 205 during the lockdown.

206 The null hypothesis $\left(\mathrm{H}_{0}\right)$ assumed an absence of differences between the pre-lockdown and 207 lockdown measurements, whereas the alternative hypothesis $\left(\mathrm{H}_{1}\right)$ assumed a directional 208 difference.

209 Bayes Factor (BF) was used to provide the alternative hypothesis's quantified evidence relative 210 to the null hypothesis. The evidence categories for Bayes factor (BF) were set as proposed by 211 Jeffreys (Jeffreys, 1998; Wetzels et al., 2011).

212 A Cauchy scale parameter of 0.707 (prior) was assigned for the effect size (Rouder et al., 2009).

213 Bayes factor robustness checks were performed. We used JASP specified wide and ultra-wide

214 priors to examine the extent to which our conclusions depend on our prior specification (van

215 Doorn et al., 2020). They display the Bayes factor as a function of the width of the Cauchy prior 216 on effect size using the wide (scale $=1$ ) and ultrawide prior $($ scale $=\sqrt{2})$.

217 Additionally, we performed pairwise Bayesian Pearson correlation tests.

218 The Bayesian statistics were performed using JASP (version 0.14.1).

219

220

221

222

223

224

225

226

227

228

229

230

231

232

233

234

235

236

237

238

239

\section{Results}

\section{Study population}

There were 326 records registered in Google Forms between 08 - 21 April 2020. Data from one participant was removed as she was 14 years old, whereas the IPAQ-LF is dedicated to adults. Records of 320 participants were analyzed. Three participants were quarantined. Out of 320 participants, 10 participants (six females, four males) indicated they had contraindications (as advised by a medical doctor) to exercise. $45.62 \%$ of the participants ( $\mathrm{n}=146,93$ women, 53 men) declared they had gardens for their own use.

Some of the records were incomplete; however, it did not disqualify them from further analysis, i.e., the missing data referred to the height or size of the living place.

Descriptive statistics are presented in Table 1. Frequencies of the participants' social status are presented in Table 2.

\section{INSERT Table 1 and 2 AROUND HERE}

\section{Physical activity before and during the lockdown}

Results of the Bayesian t-test for VPA, MPA, and Walking are presented in Table 3. 
240

241

242

243

244

245

246

247

248

249

250

251

252

253

254

255

256

257

258

259

260

261

262

263

264

265

266

267

268

269

270

271

272

273

274

275

276

277

278

279

280

\section{INSERT Table 3 AROUND HERE}

Our hypothesis that $V P A$ time before the lockdown was longer than during lockdown was anecdotally $(\mathrm{BF}=1.48)$ supported by our data (Figure 1). Although the time spent on VPA before the lockdown was longer, the difference was slightly above 9 minutes/day. Bayes factor robustness check with wide prior also anecdotally supported $\mathrm{H}_{1}(\mathrm{BF}=1.065)$. On the other hand, our data anecdotally supported $\mathrm{H}_{0}$ while the prior distribution was set to ultrawide $(\mathrm{BF}=0.76)$.

\section{INSERT Figure 1 AROUND HERE}

In contrast, our data negatively supported the hypothesis that $M P A$ before the lockdown was longer than during the lockdown (see Table 3 and Figure 2). The evidence against the alternative hypothesis $\mathrm{H}_{1}$ was strong $(\mathrm{BF}=0.046)$. It is not surprising since the average time spent on $M P A$ was longer during than before lockdown by about 2 minutes/day (Table 4). The Bayes factor robustness check with wide and ultrawide priors also supported $\mathrm{H}_{0}(\mathrm{BF}=0.032 ; \mathrm{BF}=0.023$; respectively).

\section{INSERT Figure 2 AROUND HERE}

Our data strongly supported $\mathrm{H}_{1}$ related to Walking time $(\mathrm{BF}=26.804)$. We assumed that Walking time before the lockdown was shorter than during lockdown. As shown in Table 3 and Figure 3, the mean Walking time decreased from 72.431 minutes before lockdown to 56.528 minutes/day during the lockdown. Our data still strongly supported $\mathrm{H}_{1}$ when the prior distribution was set to wide and ultrawide $(\mathrm{BF}=19.62 ; \mathrm{BF}=14.12$; respectively).

\section{INSERT Figure 3 AROUND HERE}

\section{Sedentary behavior}

We tested our $\mathrm{H}_{1}$ related to sitting time, assuming that Sitting time before lockdown will be shorter than during lockdown. The $\mathrm{H}_{1}$ was strongly (decisively) supported by our data (Figure 4). The $\mathrm{BF}=866.38$ (see Table 4). The Sitting time during lockdown increased by an average of $40 \%$, i.e., by almost 100 minutes/day compared to the pre-lockdown period. Our data extremely strongly supported $\mathrm{H}_{1}$ also with wide $(\mathrm{BF}=646.5)$ and ultrawide prior $(\mathrm{BF}=470.4)$ (Figure 5).

INSERT Table 4 AROUND HERE

INSERT Figure 4 AROUND HERE

INSERT Figure 5 AROUND HERE

Peer] reviewing PDF | (2021:10:66518:1:0:NEW 2 Dec 2021) 
281

282

283

284

285

286

287

288

289

290

291

292

293

294

295

296

297

298

299

300

301

302

303

304

305

306

307

308

309

310

311

312

313

314

315

316

317

318

319

320

\section{$V P A, M P A$, Walking, and Sitting time correlates}

One of the most bothersome restrictions during the lockdown was to stay-at-home order. People could have been physically active only in their houses and gardens unless still working professionally. Therefore, we decided to see if there were any correlations between the size of their living places $\left(\mathrm{m}^{2}\right)$ and the number of inhabitants sharing a living place. We divided the living place size by the number of inhabitants, and we correlated it with VPA, MPA, Walking, and Sitting time. We performed pairwise Bayesian Pearson correlation tests. We tested $\mathrm{H}_{1}$ that the available living space $\left(\mathrm{m}^{2} /\right.$ person) is positively correlated with $V P A, M P A$, Walking against $\mathrm{H}_{0}$, assuming there is no such correlation. The $\mathrm{H}_{1}$ was anecdotally supported by our data $(\mathrm{r}=-$ $0.052, \mathrm{BF}=0.107 ; \mathrm{r}=-0.007, \mathrm{BF}=0.071 ; \mathrm{r}=-0.016, \mathrm{BF}=0.073$; for $V P A, M P A$, Walking accordingly).

Regarding the Sitting time, we advanced the opposite hypothesis $\left(\mathrm{H}_{1}\right)$ that that available living space $\left(\mathrm{m}^{2} /\right.$ person) is negatively correlated with Sitting time. Likewise, this hypothesis was anecdotally supported by our data $(\mathrm{r}=-0.077, \mathrm{BF}=0.031)$.

To assess whether participants with their garden were more active than those without, we applied the Bayesian t-test for VPA, MPA, Walking, and Sitting time. We tested $\mathrm{H}_{1}$ that garden owners will be more physically active than the participants without gardens. All three tests did not yield supportive evidence toward these hypotheses (Table 5).

\section{INSERT Table 5 AROUND HERE}

On the other hand, we hypothesized that participants without their garden would be sitting longer than garden owners. Conversely, our data strongly supported $\mathrm{H}_{0}$, i.e., the groups were not different in this regard $(B F=0.077)$. Garden owners spent on average $405.589 \pm 552.521$ minutes/day sitting during lockdown while those without gardens $371.803 \pm 262.102$.

\section{Discussion}

Our study aimed to assess the physical activity level during the total pandemic lockdown in Poland. We advanced hypotheses that VPA, MPA, and Walking time will be much reduced during lockdown compared to the pre-lockdown period and that sitting time (Sitting) before lockdown will be shorter than during lockdown.

As hypothesized, we found that $V P A$ and Walking time decreased during lockdown compared to the pre-lockdown period. On the other hand, $M P A$ increased during the lockdown. Our data extremely strongly supported the hypothesis that Sitting time during lockdown increased. Our results align with general trends reported by other authors (Caputo and Reichert, 2020; Stockwell et al., 2021) though increased $M P A$ was a rather unexpected finding and against the advanced hypothesis. This finding has to be considered with caution. As Biernat and Piątkowska noticed (Biernat and Piątkowska, 2016), there is a tendency to overestimate PA in general. MPA is responsible for $87.5 \%$ of overestimations. Moreover, women tend to overestimate MPA in the 
321 household domain significantly. Given our sample consisted of 197 females and 123 males, this 322 tendency to overestimate $M P A$ in women could be enhanced by the unequal female/male ratio. 323 Another explanation may relate to the characteristic of MPA. Since DIY (do-it-yourself) stores 324 were open during the stay-at-home lockdown, many people started to renovate apartments and 325 houses. MPA could have been, therefore, associated with the at-home work. However, this

326

327

328

329

330

331

332

333

334

335

336

337

338

339

340

341

342

343

344

345

346

347

348

349

350

351

352

353

354

355

356

357

358

359

360 speculation has not been supported yet.

We also found that during the stay-at-home lockdown, most participants satiated WHO recommendations (World Health Organization, 2010), i.e., they were engaged in more than 150 minutes of MPA per week or 75 minutes of VPA per week (or a combination of these two). Only 32 participants $(10 \%)$ did not meet the recommended PA time. On the other hand, PA during lockdown was reduced compared to the pre-pandemic period. Our findings are consistent with most previous studies on PA during the pandemic (Stockwell et al., 2021). Twenty-nine participants did not meet the WHO recommendation before the pandemic. It is $9.06 \%$ of the sample size. Both numbers, i.e., $10 \%$ during the lockdown and $9.06 \%$ before lockdown, of physically inactive people have to be considered cautiously. Although there are no recent studies on inactivity prevalence in Poland, the available data suggest that around $30-39.9 \%$ of Polish have insufficient PA (Guthold et al., 2018).

The fact that most of the participants met the WHO recommendations is vital as PA may decrease the severity of symptoms and risk of mortality due to Covid-19 (Hudson and Sprow, 2020). However, PA is not the only factor worth taking into account; another is Sitting. In our opinion, authorities and decision-makers should consider the stay-at-home order as the last, the most detrimental restriction. As measured by the Sitting time, sedentary behavior has increased by almost 100 minutes/day, reaching 386 minutes/day on average. It means that our participants spent more than 6 hours sitting per day. Our data extremely strongly supported the hypothesis about an incline in sedentary behavior, and this finding is consistent with previous studies (Stockwell et al., 2021).

The limitations of our study have to be acknowledged. The sample is not representative. Given, we advertised our study among our friends and through social media devoted to physical activity, sports, etc., our sample may be more representative of the physically active part of the Polish population than the whole population. Lastly, we used a subjective tool, i.e., a self-reported questionnaire. It is widely reported that the PA level estimated based on self-reported questionnaires is usually overestimated compared to the more objective measures (Biernat and Piątkowska, 2016).

This paper's strength is that it is one of the very few studies on PA during the stay-at-home lockdown. Although lockdowns affected many countries' economies around the world, the restrictions introduced by many governments differed. Canceling flights, closing hotels, gyms, or 
361

362

363

364

365

366

367

368

369

370

371

372

373

374

375

376

377

378

379

380

381

382

383

384

385

386

387

388

389

390

391

392

393

394

395

396

397

398

399

400

swimming pools undoubtedly could have reduced PA. However, people who were not obliged to stay at home could have taken up other outdoor activities such as cycling, skiing, running, trekking, or any other. It is the stay-at-home order which probably made the PA less accessible in general.

It is worth emphasizing that we estimated PA at the very beginning of the pandemic, i.e., the data was gathered between 08 and 21 April 2020. People are used to pandemic regulations, and stayat-home restrictions are not so easily ordered anymore, so it is pretty plausible that PA is not so much reduced anymore. This issue could be addressed in subsequent studies.

\section{Conclusions}

In summary, VPA and Walking during stay-at-home lockdown declined. MPA and Siting increased. PA decline was not correlated with the available living place. People who have access to gardens did not demonstrate a higher PA level than those without.

We strongly recommend re-consider the negative effects the stay-at-home lockdowns have on $V P A$ and Walking, and as an effect, on health. Perhaps, allowing citizens to walk outside and let them exercise outdoor would increase both: Walking and $V P A$, and at the same time, it would decrease time spent sitting. As a result, a detrimental effect the stay-at-home order has on health could be mitigated.

\section{Acknowledgements}

We would like to thank all disseminating details and invitations to our study, specifically, our Master students and local media. The results were partially used in the students' Master dissertations (all of them in Polish). Frequentists statistics were used to analyze the data.

\section{References}

Biernat, E. (2013). Międzynarodowy Kwestionariusz Aktywności Fizycznej - Polska długa wersja (International Physical Activity Questionnaire - Polish long version). Med. Sport. $29,1-15$.

Biernat, E., and Piątkowska, M. (2016). Overestimation of physical activity by long IPAQ in a Polish nationwide study. Hygeia Public Heal. 51, 87-95.

Biernat, E., Stupnicki, R., and Gajewski, A. (2007). Międzynarodowy Kwestionariusz Aktywności Fizycznej (IPAQ)-wersja polska (International Physical Activity Questionnaire (IPAQ) - Polish version). Wych. Fiz. i Sport 51, 47-54.

Caputo, E. L., and Reichert, F. F. (2020). Studies of Physical Activity and COVID-19 During the 
401

402

403

404

405

406

407

408

409

410

411

412

413

414

415

416

417

418

419

420

421

422

423

424

425

426

427

428

429

430

431

432

433

434

435

436

437

438

439

440

441

442

443

444

445

446

Pandemic: A Scoping Review. J. Phys. Act. Heal. 17, 1275-1284. doi:10.1123/JPAH.20200406.

Cheval, B., Sivaramakrishnan, H., Maltagliati, S., Fessler, L., Forestier, C., Sarrazin, P., et al. (2020). Relationships between changes in self-reported physical activity, sedentary behaviour and health during the coronavirus (COVID-19) pandemic in France and Switzerland. J. Sports Sci. doi:10.1080/02640414.2020.1841396.

Craig, C. L., Marshall, A. L., Sjöström, M., Bauman, A. E., Booth, M. L., Ainsworth, B. E., et al. (2003). International physical activity questionnaire: 12-Country reliability and validity. Med. Sci. Sports Exerc. 35, 1381-1395. doi:10.1249/01.MSS.0000078924.61453.FB.

Ekelund, U., Steene-Johannessen, J., Brown, W. J., Fagerland, M. W., Owen, N., Powell, K. E., et al. (2016). Does physical activity attenuate, or even eliminate, the detrimental association of sitting time with mortality? A harmonised meta-analysis of data from more than 1 million men and women. Lancet 388, 1302-1310. doi:10.1016/S0140-6736(16)30370-1.

Guthold, R., Stevens, G. A., Riley, L. M., and Bull, F. C. (2018). Worldwide trends in insufficient physical activity from 2001 to 2016: a pooled analysis of 358 population-based surveys with 1.9 million participants. Lancet Glob. Heal. 6, e1077-e1086. doi:10.1016/S2214-109X(18)30357-7.

Hagströmer, M., Oja, P., and Sjöström, M. (2006). The International Physical Activity Questionnaire (IPAQ): a study of concurrent and construct validity. Public Health Nutr. 9, 755-762. doi:10.1079/phn2005898.

Hammami, A., Harrabi, B., Mohr, M., and Krustrup, P. (2020). Physical activity and coronavirus disease 2019 (COVID-19): specific recommendations for home-based physical training. Manag. Sport Leis., 1-6. doi:10.1080/23750472.2020.1757494.

Helmerhorst, H. J. F., Brage, S., Warren, J., Besson, H., and Ekelund, U. (2012). A systematic review of reliability and objective criterion-related validity of physical activity questionnaires. Int. J. Behav. Nutr. Phys. Act. 9, 103. doi:10.1186/1479-5868-9-103.

Hudson, G. M., and Sprow, K. (2020). Promoting Physical Activity During the COVID-19 Pandemic: Implications for Obesity and Chronic Disease Management. J. Phys. Act. Heal. 17, 685-687. doi:10.1123/JPAH.2020-0318.

Jeffreys, H. (1998). The theory of probability. Oxford, United Kingdom: Oxford University Press.

King, A. J., Burke, L. M., Halson, S. L., and Hawley, J. A. (2020). The Challenge of Maintaining Metabolic Health During a Global Pandemic. Sport. Med., 1-9. doi:10.1007/s40279-02001295-8.

Lee, I. M., Shiroma, E. J., Lobelo, F., Puska, P., Blair, S. N., Katzmarzyk, P. T., et al. (2012). Effect of physical inactivity on major non-communicable diseases worldwide: An analysis of burden of disease and life expectancy. Lancet 380, 219-229. doi:10.1016/S01406736(12)61031-9.

Meyer, J., McDowell, C., Lansing, J., Brower, C., Smith, L., Tully, M., et al. (2020). Changes in Physical Activity and Sedentary Behavior in Response to COVID-19 and Their Associations with Mental Health in 3052 US Adults. Int. J. Environ. Res. Public Health 17, 6469. doi:10.3390/ijerph17186469.

Pinto, A. J., Dunstan, D. W., Owen, N., Bonfá, E., and Gualano, B. (2020). Combating physical inactivity during the COVID-19 pandemic. Nat. Rev. Rheumatol., 1-2. doi:10.1038/s41584020-0427-z.

Qin, F., Song, Y., Nassis, G. P., Zhao, L., Cui, S., Lai, L., et al. (2020). Prevalence of 
447

448

449

450

451

452

453

454

455

456

457

458

459

460

461

462

463

464

465

466

467

468

469

470

471

472

473

474

475

476

477

478

479

480

481

482

483

484

485

486

487

488

489

490

491

492

Insufficient Physical Activity, Sedentary Screen Time and Emotional Well-Being During the Early Days of the 2019 Novel Coronavirus (COVID-19) Outbreak in China: A National Cross-Sectional Study. Lancet. doi:10.2139/ssrn.3566176.

Rhodes, R. E., Liu, S., Lithopoulos, A., Zhang, C., and Garcia-Barrera, M. A. (2020). Correlates of Perceived Physical Activity Transitions during the COVID-19 Pandemic among Canadian Adults. Appl. Psychol. Heal. Well-Being 12, 1157-1182. doi:10.1111/aphw.12236.

Rouder, J. N., Speckman, P. L., Sun, D., Morey, R. D., and Iverson, G. (2009). Bayesian t tests for accepting and rejecting the null hypothesis. Psychon. Bull. Rev. 16, 225-237. doi:10.3758/PBR.16.2.225.

Schmidt, S. C. E., Anedda, B., Burchartz, A., Eichsteller, A., Kolb, S., Nigg, C., et al. (2020). Physical activity and screen time of children and adolescents before and during the COVID19 lockdown in Germany: a natural experiment. Sci. Rep. 10. doi:10.1038/S41598-02078438-4.

Sjöström, M., Ainsworth, A., Bauman, A., Bull, F., Hamilton-Craig, C., and Sallis, J. (2005). Guidelines for data processing analysis of the International Physical Activity Questionnaire (IPAQ) - Short and long forms. Available at: https://www.scienceopen.com/document?vid=b223350f-d159-4043-9b48-e2031f210a3c [Accessed August 25, 2020].

Stockwell, S., Trott, M., Tully, M., Shin, J., Barnett, Y., Butler, L., et al. (2021). Changes in physical activity and sedentary behaviours from before to during the COVID-19 pandemic lockdown: a systematic review. BMJ Open Sport Exerc. Med. 7, 960. doi:10.1136/bmjsem2020-000960.

Terwee, C. B., Mokkink, L. B., Van Poppel, M. N. M., Chinapaw, M. J. M., Van Mechelen, W., and De Vet, H. C. W. (2010). Qualitative attributes and measurement properties of physical activity questionnaires: A checklist. Sport. Med. 40, 525-537. doi:10.2165/11531370000000000-00000.

Tison, G. H., Avram, R., Kuhar, P., Abreau, S., Marcus, G. M., Pletcher, M. J., et al. (2020). Worldwide Effect of COVID-19 on Physical Activity: A Descriptive Study. Ann. Intern. Med. 173, 767-770. doi:10.7326/M20-2665.

United Nations Department of Economic and Social Affairs (2020). The impact of COVID-19 on sport, physical activity and well-being and its effects on social development. Available at: https://www.un.org/development/desa/dspd/2020/05/covid-19-sport/ [Accessed June 3, 2020].

van Doorn, J., van den Bergh, D., Böhm, U., Dablander, F., Derks, K., Draws, T., et al. (2020). The JASP guidelines for conducting and reporting a Bayesian analysis. Psychon. Bull. Rev., 1-14. doi:10.3758/s13423-020-01798-5.

Vitale, J. A., Bonato, M., Borghi, S., Messina, C., Albano, D., Corbetta, S., et al. (2020). HomeBased Resistance Training for Older Subjects during the COVID-19 Outbreak in Italy: Preliminary Results of a Six-Months RCT. Int. J. Environ. Res. Public Heal. 2020, Vol. 17, Page 9533 17, 9533. doi:10.3390/IJERPH17249533.

Wetzels, R., Matzke, D., Lee, M. D., Rouder, J. N., Iverson, G. J., and Wagenmakers, E.-J. (2011). Statistical Evidence in Experimental Psychology: An Empirical Comparison Using 855 t Tests. Perspect. Psychol. Sci. 6, 291-8. doi:10.1177/1745691611406923.

World Health Organization (2010). Global Recommendations On Physical Activity For Health. Available at: https://www.who.int/dietphysicalactivity/publications/9789241599979/en/.

Peer) reviewing PDF | (2021:10:66518:1:0:NEW 2 Dec 2021) 
493 World Health Organization (2020). Be Active during COVID-19. Available at:

$494 \mathrm{https} / / \mathrm{www} . w h o . i n t / e m e r g e n c i e s / d i s e a s e s / n o v e l-c o r o n a v i r u s-2019 / q u e s t i o n-a n d-a n s w e r s-$ $495 \mathrm{hub} / \mathrm{q}-\mathrm{a}-d e t a i l /$ be-active-during-covid-19 [Accessed June 3, 2020].

496 World Medical Association (2013). World Medical Association Declaration of Helsinki: Ethical 497 Principles for Medical Research Involving Human Subjects. JAMA 310, 2191-2194.

498 doi:10.1001/JAMA.2013.281053.

499 
Table $\mathbf{1}$ (on next page)

Descriptive statistics 
1

2 Table 1 Descriptive statistics.

\begin{tabular}{lrrrrrrrrr}
\hline & \multicolumn{2}{c}{ Age (years) } & \multicolumn{2}{c}{ Height (cm) } & \multicolumn{2}{c}{ Body mass (kg) } & \multicolumn{2}{c}{ Living place size (m2) } \\
\hline & Female & Male & Female & Male & Female & Male & Female & \multicolumn{1}{c}{ Male } \\
\hline Valid & 197 & 121 & 197 & 123 & 197 & 123 & 197 & 121 \\
\hline Mean & 32.858 & 35.95 & 166.198 & 180.374 & 62.423 & 81.39 & 95.308 & 91.727 \\
\hline SD & 12.001 & 13.83 & 5.848 & 5.805 & 10.047 & 11.867 & 61.645 & 67.937 \\
\hline Minimum & 18 & 17 & 150 & 167 & 42 & 59 & 24 & 10 \\
\hline Maximum & 76 & 75 & 180 & 194 & 98 & 130 & 400 & 413
\end{tabular}

3

4

5 
Table 2 (on next page)

Frequencies ( $n$ ) of participants' social status 
1

2 Table 2 Frequencies (n) of participants' social status.

\begin{tabular}{|c|c|c|c|c|}
\hline Sex & Social status & Frequency & Percent & $\begin{array}{c}\text { Cumulative } \\
\text { Percent }\end{array}$ \\
\hline \multirow{9}{*}{ Female } & farmer & 1 & 0.508 & 0.508 \\
\hline & maternity leave & 4 & 2.03 & 2.538 \\
\hline & pensioner & 7 & 3.553 & 6.091 \\
\hline & schoolchild & 7 & 3.553 & 9.645 \\
\hline & student & 63 & 31.98 & 41.624 \\
\hline & unemployed & 6 & 3.046 & 44.67 \\
\hline & white-collar worker & 93 & 47.208 & 91.878 \\
\hline & worker & 16 & 8.122 & 100 \\
\hline & Total & 197 & 100 & \\
\hline \multirow{9}{*}{ Male } & farmer & 0 & 0 & 0 \\
\hline & maternity leave & 0 & 0 & 0 \\
\hline & pensioner & 3 & 2.439 & 2.439 \\
\hline & schoolchild & 6 & 4.878 & 7.317 \\
\hline & student & 28 & 22.764 & 30.081 \\
\hline & unemployed & 1 & 0.813 & 30.894 \\
\hline & white-collar worker & 75 & 60.976 & 91.87 \\
\hline & worker & 10 & 8.13 & 100 \\
\hline & Total & 123 & 100 & \\
\hline
\end{tabular}

3 


\section{Table 3 (on next page)}

Bayesian paired sample t-test results for VPA, MPA, and Walking before and during the lockdown

The alternative hypotheses specify that VPA, MPA, and Walking time before lockdown are longer than during lockdown for all tests. SD - standard deviation, SE - standard error of the mean. $B F+0$ : Bayes factor that quantifies evidence for the one-sided alternative hypothesis that group one $>$ group two, relative to the null hypothesis. 
1

2 Table 3 Bayesian paired sample t-test results for $V P A, M P A$, and Walking before and during the 3 lockdown. The alternative hypotheses specify that VPA, MPA, and Walking time before

4 lockdown are longer than during lockdown for all tests. SD - standard deviation, SE - standard

5 error of the mean. $\mathrm{BF}+0$ : Bayes factor that quantifies evidence for the one-sided alternative

6 hypothesis that group one $>$ group two, relative to the null hypothesis.

7

\begin{tabular}{|c|c|c|c|c|c|c|c|c|c|}
\hline \multirow[b]{2}{*}{ Activity } & \multirow[b]{2}{*}{ Comparison } & \multirow[b]{2}{*}{$\mathbf{N}$} & \multirow[b]{2}{*}{$\begin{array}{c}\text { Mean } \\
\text { (min/day) }\end{array}$} & \multirow[b]{2}{*}{ SD } & \multirow[b]{2}{*}{ SE } & \multicolumn{2}{|c|}{$\begin{array}{l}\text { 95\% Credible } \\
\text { Interval }\end{array}$} & \multicolumn{2}{|c|}{$\begin{array}{l}\text { Bayesian Paired } \\
\text { Samples T-Test }\end{array}$} \\
\hline & & & & & & Lower & Upper & $\mathrm{BF}_{+0}$ & error \% \\
\hline \multirow[b]{2}{*}{ VPA } & $\begin{array}{l}\text { Before } \\
\text { lockdown }\end{array}$ & 320 & 56.725 & 53.1 & 2.968 & 50.885 & 62.565 & \multirow{2}{*}{1.48} & \multirow[t]{2}{*}{$\sim 7.046 \mathrm{e}-8$} \\
\hline & $\begin{array}{l}\text { During } \\
\text { lockdown }\end{array}$ & 320 & 47.362 & 50.88 & 2.844 & 41.767 & 52.958 & & \\
\hline \multirow[b]{2}{*}{ MPA } & $\begin{array}{l}\text { Before } \\
\text { lockdown }\end{array}$ & 320 & 66.394 & 58.328 & 3.261 & 59.979 & 72.809 & \multirow[t]{2}{*}{0.046} & \multirow[t]{2}{*}{$\sim 0.001$} \\
\hline & $\begin{array}{l}\text { During } \\
\text { lockdown }\end{array}$ & 320 & 68.375 & 59.197 & 3.309 & 61.864 & 74.886 & & \\
\hline \multirow[b]{2}{*}{ Walking } & $\begin{array}{l}\text { Before } \\
\text { lockdown }\end{array}$ & 320 & 72.431 & 62.22 & 3.478 & 65.588 & 79.274 & \multirow[t]{2}{*}{26.804} & \multirow[t]{2}{*}{$\sim 2.265 \mathrm{e}-4$} \\
\hline & $\begin{array}{l}\text { During } \\
\text { lockdown }\end{array}$ & 320 & 56.528 & 59.154 & 3.307 & 50.022 & 63.034 & & \\
\hline
\end{tabular}

8 


\section{Table 4 (on next page)}

Bayesian paired sample t-test results for Sitting time before and during the lockdown

The alternative hypothesis specifies Sitting time before the lockdown was shorter than during lockdown. SD - standard deviation, SE - standard error of the mean. $\mathrm{BF}_{-}$: Bayes factor that quantifies evidence for the one-sided alternative hypothesis that group one < group two, relative to the null hypothesis. 
1 Table 4 Bayesian paired sample t-test results for Sitting time before and during the lockdown.

2 The alternative hypothesis specifies Sitting time before the lockdown was shorter than during

3 lockdown. SD - standard deviation, $\mathrm{SE}$ - standard error of the mean. $\mathrm{BF}_{-0}$ : Bayes factor that

4 quantifies evidence for the one-sided alternative hypothesis that group one $<$ group two, relative

5 to the null hypothesis.

6

$\begin{array}{lc}\text { 95\% Credible } & \text { Bayesian Independent } \\ \text { Interval } & \text { Samples T-Test }\end{array}$

\begin{tabular}{|c|c|c|c|c|c|c|c|c|c|}
\hline Activity & Comparison & $\mathbf{N}$ & $\begin{array}{c}\text { Mean } \\
\text { (min/day) }\end{array}$ & SD & SE & Lower & Upper & $\mathrm{BF}_{-0}$ & error $\%$ \\
\hline \multirow[t]{2}{*}{ Sitting } & $\begin{array}{l}\text { Before } \\
\text { lockdown }\end{array}$ & 320 & 276.306 & 168.538 & 9.422 & 257.77 & 294.843 & \multirow[t]{2}{*}{866.38} & \multirow[t]{2}{*}{$\sim 8.902 \mathrm{e}-9$} \\
\hline & $\begin{array}{l}\text { During } \\
\text { lockdown }\end{array}$ & 320 & 386.087 & 420.157 & 23.487 & 339.878 & 432.297 & & \\
\hline
\end{tabular}

7

8 


\section{Table 5 (on next page)}

Bayesian independent sample t-test results for VPA, MPA, Walking time during the lockdown in participants with and without own gardens

For all tests, the alternative hypothesis $\mathrm{H} 1$ specifies that the group "no garden" is less than group "own garden". SD - standard deviation, SE - standard error of the mean. BF.- Bayes factor that quantifies evidence for the one-sided alternative hypothesis that group one $<$ group two, relative to the null hypothesis. 
1 Table 5 Bayesian independent sample t-test results for $V P A, M P A$, Walking time during the 2 lockdown in participants with and without own gardens. For all tests, the alternative hypothesis 3 H1 specifies that the group "no garden" is less than group "own garden". SD - standard 4 deviation, $\mathrm{SE}$ - standard error of the mean. $\mathrm{BF}_{-0}$ : Bayes factor that quantifies evidence for the 5 one-sided alternative hypothesis that group one $<$ group two, relative to the null hypothesis.

6

\begin{tabular}{|c|c|c|c|c|c|c|c|c|c|}
\hline \multirow[b]{2}{*}{ Activity } & \multirow[b]{2}{*}{ Comparison } & \multirow[b]{2}{*}{$\mathbf{N}$} & \multirow[b]{2}{*}{$\begin{array}{c}\text { Mean } \\
(\mathrm{min} / \text { day })\end{array}$} & \multirow[b]{2}{*}{ SD } & \multirow[b]{2}{*}{ SE } & \multicolumn{2}{|c|}{$\begin{array}{l}\text { 95\% Credible } \\
\text { Interval }\end{array}$} & \multicolumn{2}{|c|}{$\begin{array}{c}\text { Bayesian Independent } \\
\text { Samples T-Test }\end{array}$} \\
\hline & & & & & & Lower & Upper & $\mathrm{BF}_{-0}$ & error $\%$ \\
\hline \multirow{3}{*}{$\begin{array}{l}\text { VPA during } \\
\text { lockdown }\end{array}$} & No garden & 173 & 44.434 & 47.805 & 3.635 & 37.259 & 51.608 & \multirow{3}{*}{0.321} & \multirow{3}{*}{$\sim 1.165 \mathrm{e}-4$} \\
\hline & & & & & & & & & \\
\hline & Own garden & 146 & 49.925 & 53.35 & 4.415 & 41.198 & 58.651 & & \\
\hline \multirow{2}{*}{$\begin{array}{l}\text { MPA during } \\
\text { lockdown }\end{array}$} & No garden & 173 & 64.277 & 58.072 & 4.415 & 55.563 & 72.992 & \multirow{2}{*}{0.456} & \multirow{2}{*}{$\sim 1.145 \mathrm{e}-5$} \\
\hline & Own garden & 146 & 72.466 & 59.885 & 4.956 & 62.67 & 82.261 & & \\
\hline \multirow{2}{*}{$\begin{array}{c}\text { Walking } \\
\text { during } \\
\text { lockdown }\end{array}$} & No garden & 173 & 58.624 & 60.726 & 4.617 & 49.511 & 67.737 & \multirow{2}{*}{0.072} & \multirow{2}{*}{$\sim 5.130 \mathrm{e}-6$} \\
\hline & Own garden & 146 & 53.199 & 56.59 & 4.683 & 43.942 & 62.455 & & \\
\hline
\end{tabular}

7 
Figure 1

Prior and posterior VPA

Displays the prior (dashed line) and posterior (solid line) distribution of the effect size under the alternative hypothesis; the gray circles represent the height of the prior and the posterior density at effect size delta $=0$. The horizontal solid line represents the width of the $95 \%$ credible interval of the posterior.

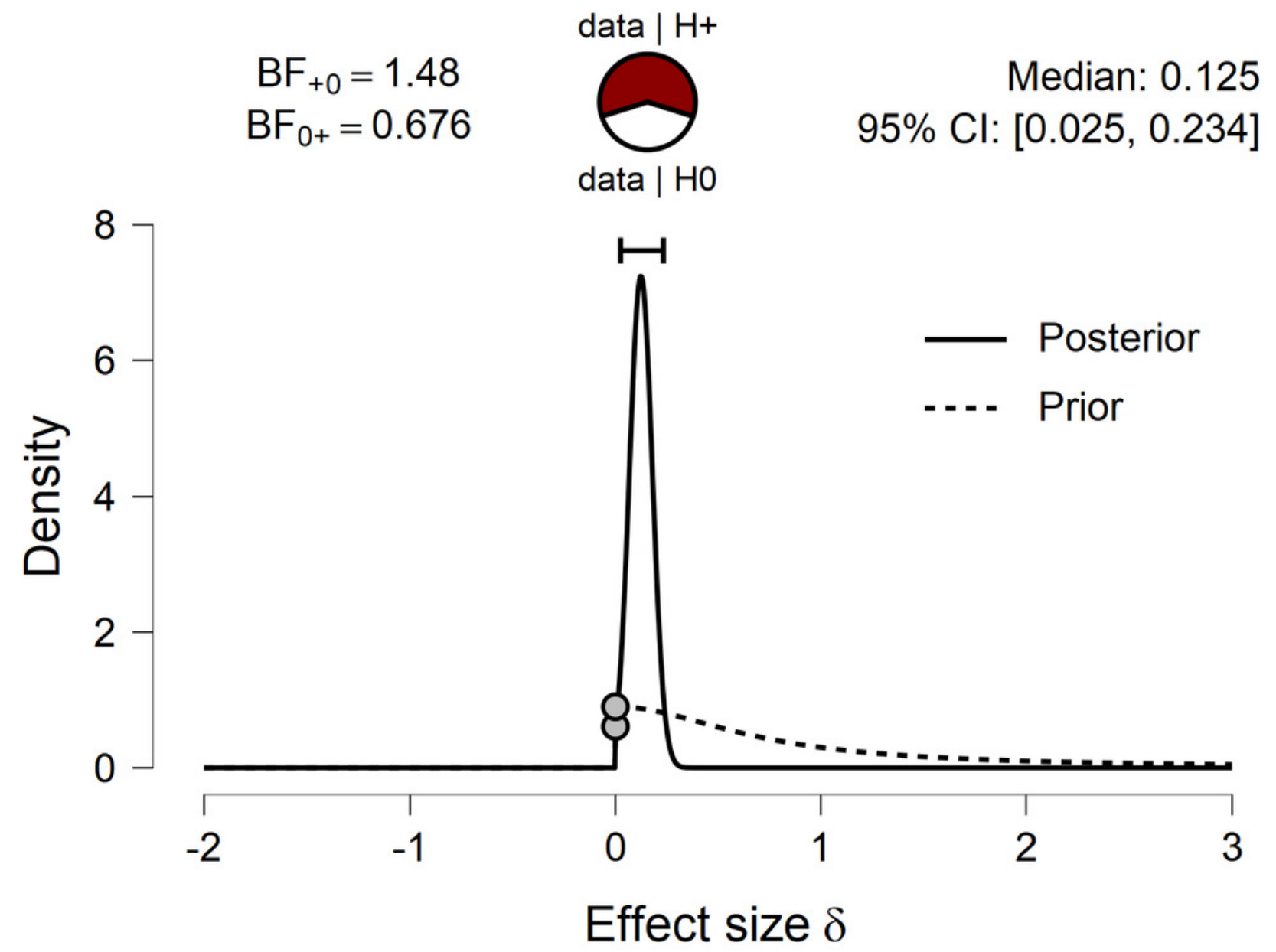

Legend:

$\mathrm{CI}$ - confidential intervals.

Pizza plot: Data|H0 - data supporting null hypothesis; Data|H+ - data supporting alternative hypothesis.

$\mathrm{BF}_{+0}$ : Bayes factor that quantifies evidence for the one-sided alternative hypothesis that group one $>$ group two, relative to the null hypothesis.; $\mathrm{BF}_{0+}$ : Bayes factor that quantifies evidence for the null hypothesis, relative to the one-sided alternative hypothesis that group one $>$ group two. 


\section{Figure 2}

Prior and posterior MPA.

Displays the prior (dashed line) and posterior (solid line) distribution of the effect size under the alternative hypothesis; the gray circles represent the height of the prior and the posterior density at effect size delta $=0$. The horizontal solid line represents the width of the $95 \%$ credible interval of the posterior. 

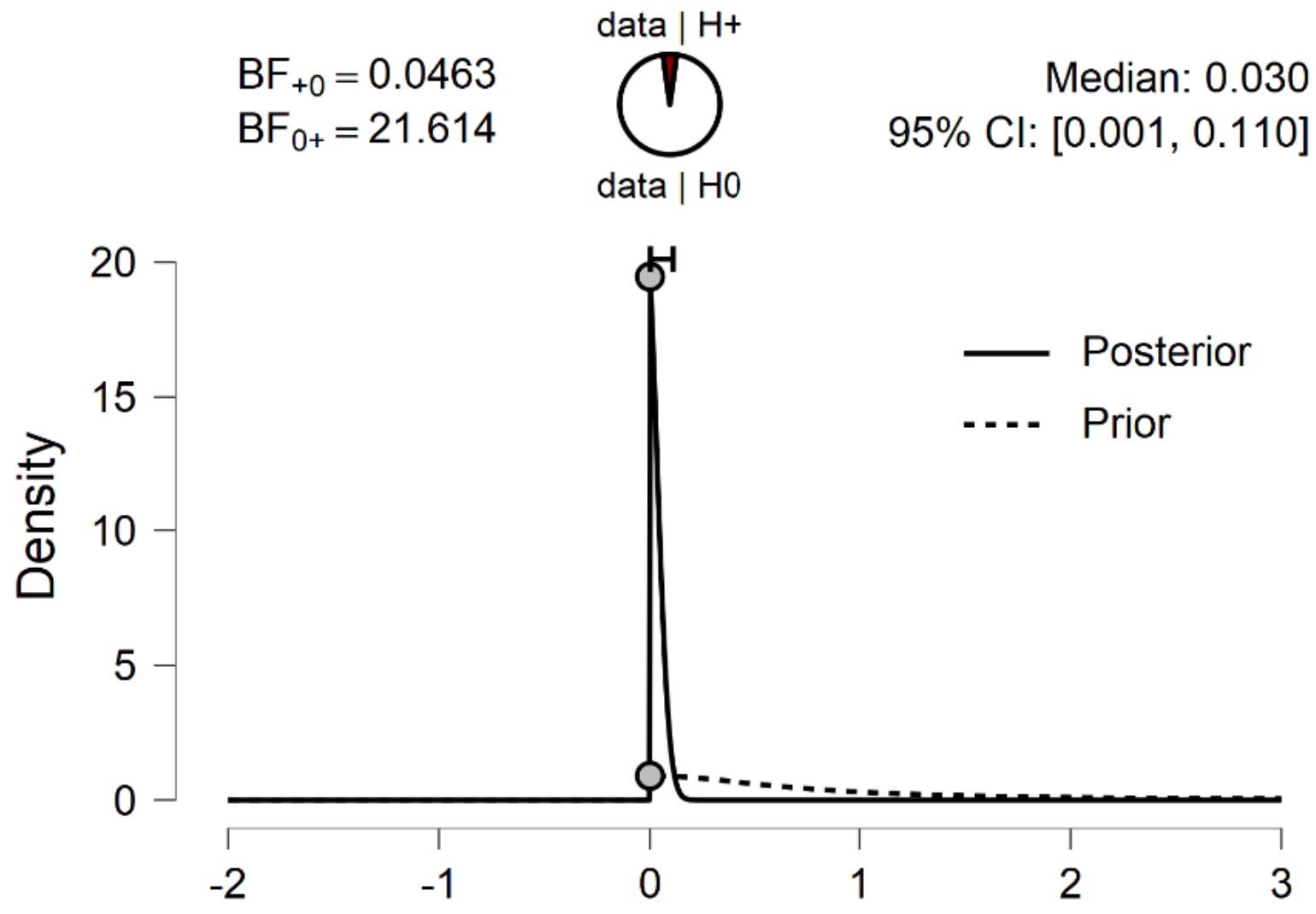

\section{Effect size $\delta$}

\section{Legend:}

CI - confidential intervals.

Pizza plot: Data|HO - data supporting null hypothesis; Data|H+ - data supporting alternative hypothesis.

$\mathrm{BF}+0$ : Bayes factor that quantifies evidence for the one-sided alternative hypothesis that group one > group two, relative to the null hypothesis.; $\mathrm{BF}_{0+}$ : Bayes factor that quantifies evidence for the null hypothesis, relative to the one-sided alternative hypothesis that group one > group two. 


\section{Figure 3}

Prior and posterior Walking.

Displays the prior (dashed line) and posterior (solid line) distribution of the effect size under the alternative hypothesis; the gray circles represent the height of the prior and the posterior density at effect size delta $=0$. The horizontal solid line represents the width of the $95 \%$ credible interval of the posterior. 


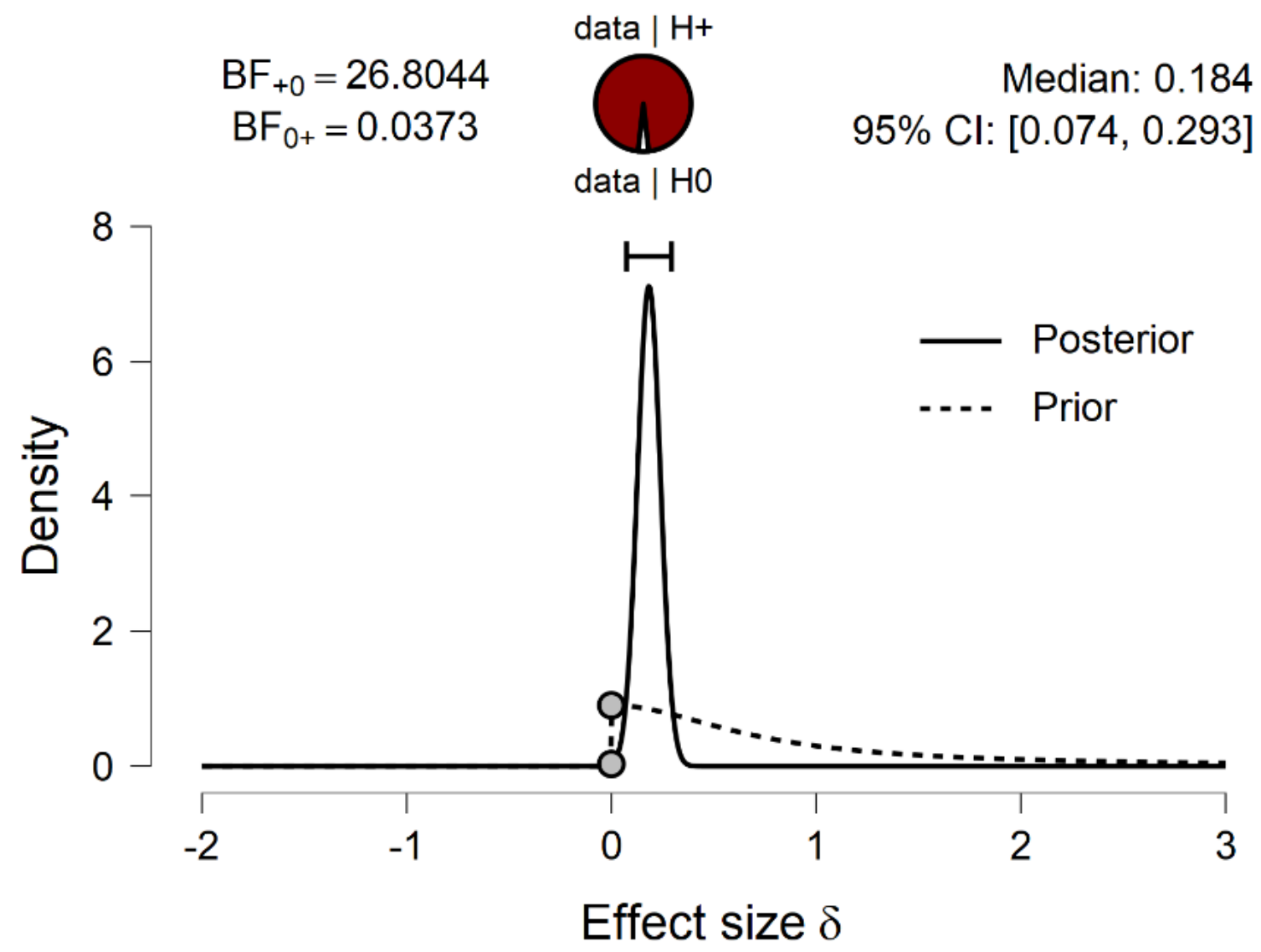

\section{Legend:}

$\mathrm{CI}$ - confidential intervals.

Pizza pl ot: Data|H0 - data supporting null hypothesis; Data|H+ - data supporting alternative hypothesis.

$\mathrm{BF}_{+0}$ : Bayes factor that quantifies evidence for the one-sided alternative hypothesis that group one $>$ group two, relative to the null hypothesis.; $\mathrm{BF}_{0+}:$ Bayes factor that quantifies evidence for the null hypothesis, relative to the one-sided alternative hypothesis that group one $>$ group two. 


\section{Figure 4}

Prior and posterior of Sitting.

Displays the prior (dashed line) and posterior (solid line) distribution of the effect size under the alternative hypothesis; the gray circles represent the height of the prior and the posterior density at effect size delta $=0$. The horizontal solid line represents the width of the $95 \%$ credible interval of the posterior. 


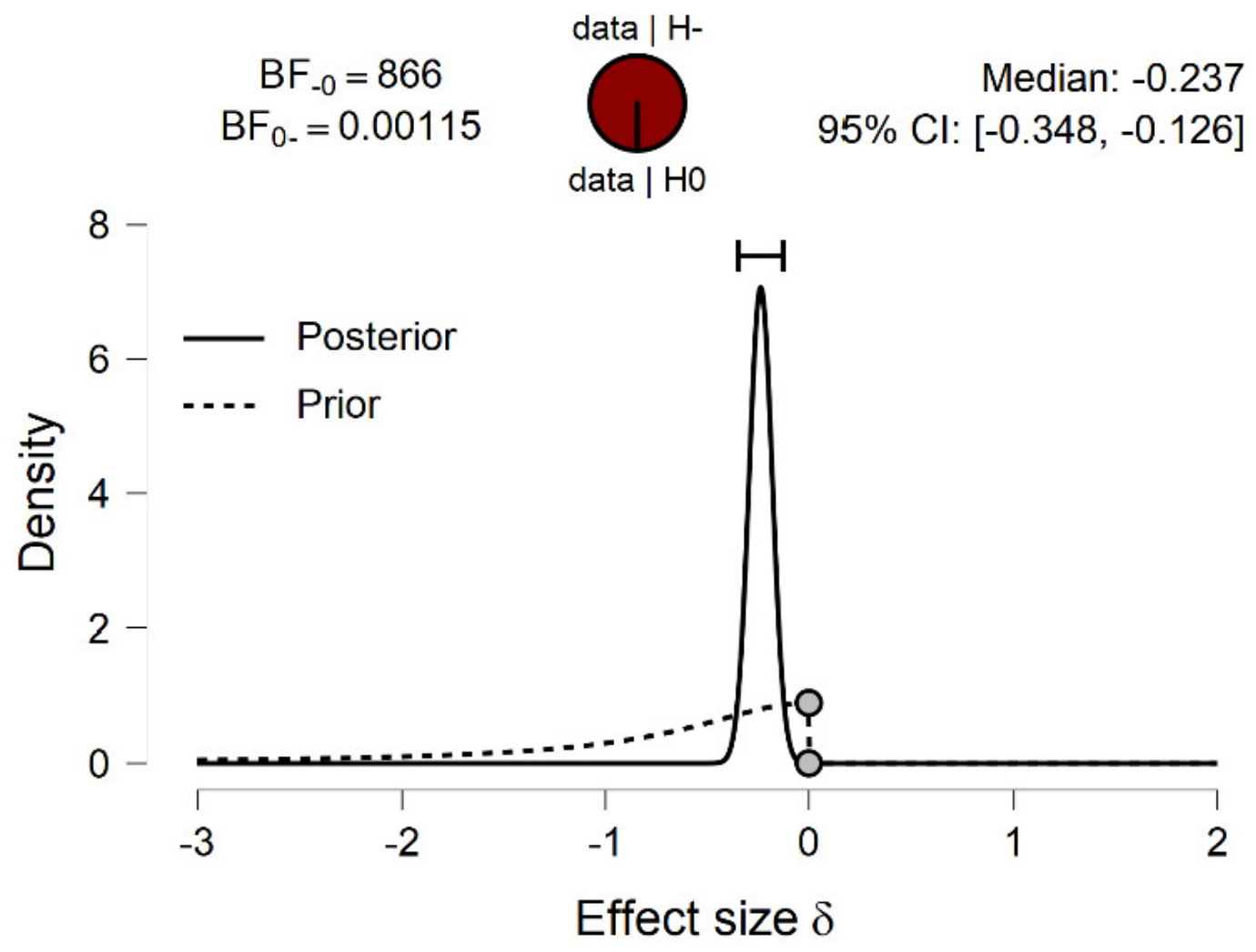

Legend:

CI - confidential intervals.

Pizza plot: Data|H0 - data supporting null hypothesis; Data|H+ - data supporting al ternative hypothesis.

$\mathrm{BF}_{-0}$ : Bayes factor that quantifies evidence for the one-sided al ternative hypothesis that group one $<$ group two,

relative to the null hypothesis; $\mathrm{BF}_{0}$ : Bayes factor that quantifies evidence for the null hypothesis, relative to the onesided al ternative hypothesis that group one < group two. 
Figure 5

Bayes factor robustness check for Sitting

Displays the Bayes factor as a function of the width of the Cauchy prior on effect size. The black circle represents the Bayes factor computed with a wide prior; the white circle represents the Bayes factor computed with an ultrawide prior; the gray circle represents the Bayes factor computed with the user-defined prior.

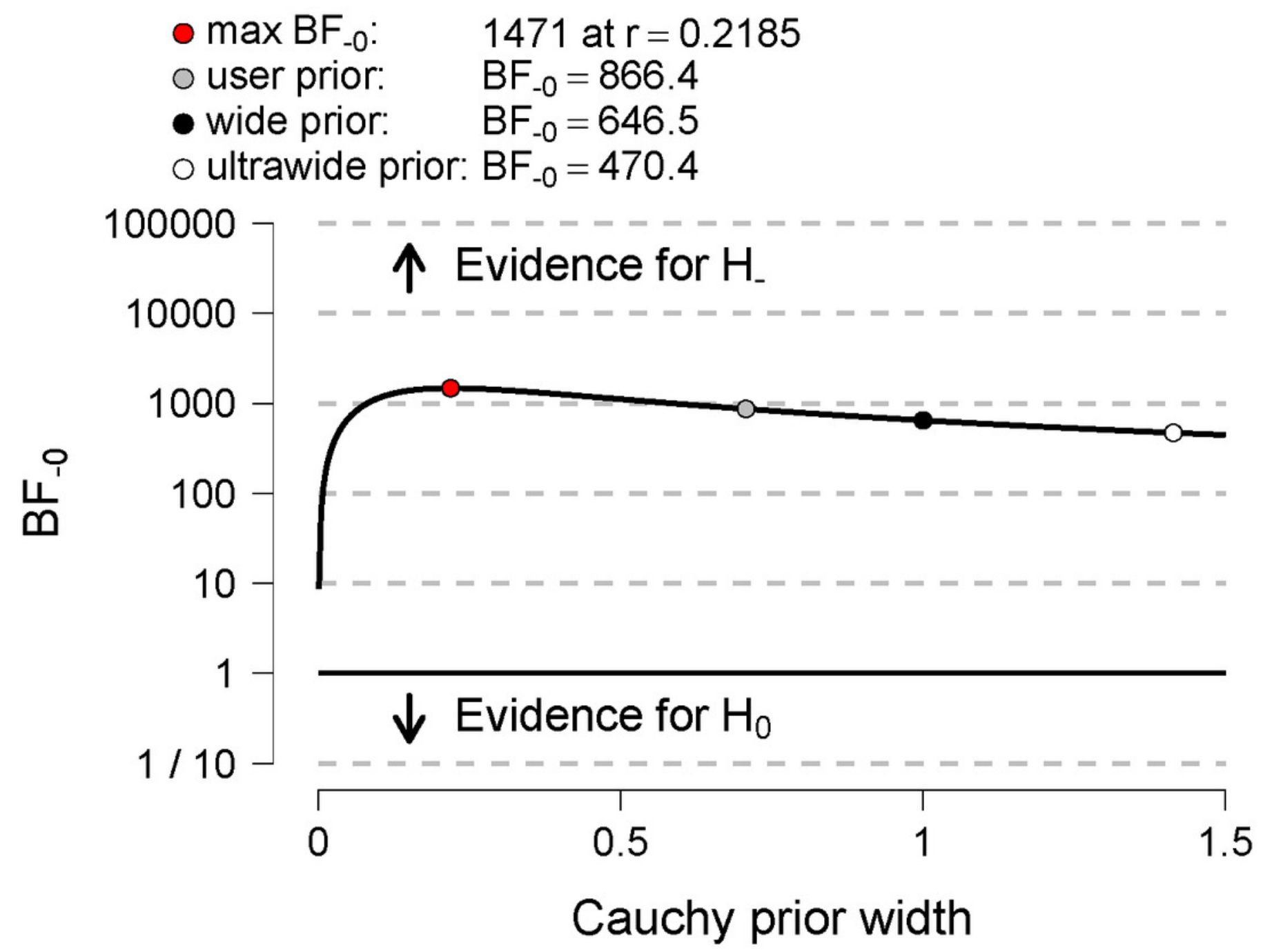

